liberty to kick an attendant and then go scot free. I would punish all such cases but I would make the punishment proportionate to the mental capacity of the individual. We should not judge such cases by ordinary standards or punish them by ordinary punishments. We must recognise that there now exists a class not adapted to their environment--individuals who have been well described as of "attenuated responsibility" ; these ought not to be exposed to temptations greater than we know they can bear. Considerations such as these apply particularly in the case of feeble-minded girls. I need hardly remind you that in girls who are lacking in moral and intellectual qualities the lower passions are often strong and always uncontrolled. For this reason a large number of the inmates of penitentiary homes are found to be feeble-minded.

The objection may at once be raised that if the feebleminded and the morally insane are to be put in industrial homes the expense to the community will be great. Certainly it means expense and in the first instance an increased outlay; ultimately the expenditure will be small compared with that already sustained by the healthy members of the community in the form of rates and private charity. At present, though many people do not realise it, we are paying for the support of the feeble-minded and not only paying but paying at a ridiculously high rate. For $I$ am not contending that it is necessary suddenly to start shutting up a large group who have never been shut up before. I propose nothing really new. I only ask for a modification-a rational modification-of our present system of prisons, workhouse maternity wards, penitentiaries, reformatories, \&c. $I$ only ask for an extension of the methods adopted at Borstal prison with such gratifying results-methods which should have been adopted years ago. We do shut these cases up but we shut them up at the wrong time and in the wrong place. Just to illustrate this point think of the career of a feeble-minded boy who came under my notice. He absconded from a working boys' home and went to work on a farm; he left that to enlist in the army but was turned out as useless afterwards he was convicted of bicycle stealing and sent to prison. Since 1901 he has not been heard of, but I am sure if he is alive he is not living at his own expense. With feebleminded girls the folly of the present system of ignoring them till a crisis is reached is even more apparent. What actually happens with many of that class? Well, you know the usual programme as well as I do ; maternity ward of the workhouse. penitentiary, prison, workhouse again. 'This is no fancied picture ; I can give you many instances of such a career. There is a feeble-minded woman in Birmingham who has been admitted to the maternity wards of the work. house nine times and who is now on the streets selling matches, a disgrace to the city and to our present legislation. Putting other considerations on one side it would surely be more economical to take charge of such a one from the first and place her in a home where she could be trained and protected. Think of all the costly institutions that have to be maintained for such cases under the present system. Think of all the elaborate machinery that must be kept in good working order. I am sure our magistrates would be glad if they could commit such people to the proper institutions from the first. A few weeks ago there was a notorious case in Birmingham of attempted suicide by a girl, aged 17 years, who had several times run away from home and who had nearly taken her own life before. She was allowed by the bench to be taken home but immediately went off again. When I saw ber shortly afterwards in a night shelter I found that it was a case of hystero-epilepsy.

The Birmingham After-care Committee has long realised the truth of what I have just said; feeling, however, that fact was better than theory it decided to conduct an inquiry into the number of the feeble-minded in the various charitable institutions for young people in and around Birmingham. We did not concern ourselves, you must observe, with institutions intended primarily for the feebleminded such as Miss Stacey's but with ordinary institutions intended for ordinary people. I visited 16 such institutions. I will first give you somewhat full details with regard to a Magdalen Home of which I have been the honorary medical officer for some years. This home, like most penitentiaries, is filled with young girls, girls in their teens, some of them very young. Of 97 consecutive cases 26 were feeble-minded, 7 were cases of moral insanity, one was epileptic, one was lunatic, and one was deaf and dumb. In fact, over 37 per cent. were mentally deficient. I have here classified as morally insane girls who were sharp and intelligent but without sense of honour or modesty and who were insusceptible to moral or religious teaching, thereby differing largely from the majority; nothing could stop them from lying or from stealing from their fellows. 'The subsequent careers amply justify our contention that such cases come ultimately on private charity or the rates. Thus the lunatic is in an asylum and the epileptic in the workhouse ; of the 26 feeble. minded 12 are in the workhouse, one in an idiot asylum, one in a lunatic asylum, one in prison, and 4 in special homes. Altogether 19 out of the 26 feeble-minded are known in the space of four years to have again become a burden on the public. High as is the percentage of feebleminded in this home it is confirmed by the numbers in other homes for girls. Even in a home where special precautions are taken to exclude the feeble-minded by means of preliminary inquiries and a medical examination $I$ found among four girls one mentally deficient. She was a typical microcephalic. On inquiry I found she was peculiar and difficult to manage; she had threatened to commit suicide. Her father was known to have been a drunkard and her sister had been in a Magdalen Home. Without further details I may say that of the 862 young people who came under observation 94, or nearly 11 per cent., were defective to such a degree as to require permanent care. In two girls' night shelters I have recently visited the number of weaklings is distressing; among $29 \mathrm{I}$ only found 8 normal individuals.

The principal causes of feeble-mindedness are : (1) deficient nutrition in the early years of life ; (2) hereditary tendency to consumption; (3) descent from an insane or criminal stock; and (4) chronic alcoholism of one or both parents. In the moral, or rather the immoral, cases one of the latter factors is almost always to be detected-that is to sas, a criminal, insane, or alcoholic inheritance.

Now, in attempting to solve the problem we must take a broad view. While thinking of the exigencies of the moment we must also look to the future. In the first place we must provide industrial homes for the feeble-minded already existing; we must do this partly for their own sake and even more with the object of preventing the nation being saddled with their offspring-other degenerates. We must decide to keep them, not for two years, not till they are 16 , or 18 , or 21 years of age, but till they are fit to mingle with the rest of the community. When we send a lunatic to an asylum we do not send him for some arbitrary period but till he is better. So should we act with these unfortunates. The work in the homes should be manual, not intellectual. Then we must educate the people in matters of hygiene. We must impress upon them that, as with most other forms of disease, these mental and moral defects do not come by chance but are the natural and inevitable result of breaking natural laws. Take the alcohol question alone. Does anyone who has thought about social reform at all and inquired into the family history of the inmates of our prisons and reformatories think that so long as the expenditure on drink in this country shows the appalling total of $£ 180,000,000$ a year we shall shake ourselves free from this terrible incubus of degenerates, criminals, epileptics, lunatics, and feeble-minded? Why, the figure I have mentioned has been calculated to represent an annual average outlay of $£ 18$ per family for the non-abstaining working classes and of $\$ 46$ per family for the other non-abstaining classes. Let me just repeat-£18 per family a year for the non-abstaining working classes. We must therefore do our utmost to preach the gospel of simple food, of temperance, of fresh air, and of hard work. By these means we shall at last solve the problem. Birmingham.

\section{ON STREPTOCOCCAL INFECTION AND THE USE OF ANTISTREPTOCOCCIC SERUM.}

By S. ANDERSON, M.B., C.M., B.Sc. GLasG., CAP'TAIY, I.M.S. ; CIVIL SURGEON, GOALPARA, ASSAM, INDIA.

'THAT antistreptococcic serum is of value in a number of cases of streptococcal infection has been proved in the results which have from time to time been published in the. medical journals. Now that in practice a polyvalent serum can be obtained it is more likely that one will be able to. "hit off" as it were a serum antitoxic to the particular. strain of streptococcus found in the varying diseases produced 
by that organism. In a paper on Chronic Streptococcic Endocarditis" Dr. T. J. Horder says: "The ideal serum for the treatment of any particular patient suffering from streptococcus infection must be one obtained by the use of the organism actually causing the disease in that patient, for this serum can alone be guaranteed to be specifically associated with the causal agent of the disease." No one will be bold enough to deny that in such a case where access was obtainable to a properly equipped laboratory in which the nature of the infection could be studied and an immune serum prepared conforming to the above principle this was the ideal treatment. When, however, in an Indian mofussil station one is confronted with severe cases mainly of a sapræmic nature there is no valid objection to the use of one or all of the various antistreptococcic sera available or the market. For whilst this serum seems to be the one in which the best therapeutical success has been attained, and it is impossible in a given case to say whether or not the patient will be benefited, yet to give the patient the best chance of recovery and immediately the infection is recognised clinically it is necessary that the serum should be applied as soon as possible before much toxin has formed.

During the past year in the two cases in which I used the serum it was to my mind difficult to get away from the finding that the patient's recovery was in great part attributable to its use, since most septicæmic conditions rarely recover spontaneously and in most the prognosis is grave. Considering that in the previous record of cases which had been treated with antistreptococcic serum and that even yet the makers of "polyvalent" sera state in the directions for its use: "The treatment of streptococcal infection by the injection of a bacterial serum is still in the experimental stage, and its results appear to be both uncertain and variable;" therefore the reporting of successes does not in the present state of our knowledge mean any real advance in the matter of serum therapy. The serum used was that prepared by Messrs. Burroughs, Wellcome, and Co., and in acute cases requiring immediate aid it can be recommended, since it seems to be possessed of sufficient of the "immune body." In future, however, as recommended by Lieutenant F. P. Mackie, I.M.S., ${ }^{2}$ if I were again treating cases with antistreptococcic sera, I should procure sarnples from as many sources as possible and give them alternately, on the principle that one would be more likely to " hit off" the particular variety of coccus causing the disease under treatment.

CASE 1.-The patient, a Hindoo female, aged 35 years, the mother of eight children, enjoyed apparent good health up to the latter part of her last pregnancy when she began to complain of an itching sensation inside the right ear. Shortly after delivery she noticed a thin sanious discharge commencing from that ear and in about a month's time it became suddenly inflamed, the orifice was almost completely blocked with matter, and she suffered from intense headache and severe pain in the ear night and day; accompanying these symptoms the discharge became purulent and the temperature rose daily to about $102^{\circ} \mathrm{F}$. Under ordinary treatment these symptoms were alleviated and the temperature came down to $99^{\circ}$. A profuse discharge continued from the ear and in a week's time-viz., on April 17th-the patient was suddenly seized with rigor followed by fever, the temperature rising to $103^{\circ}$. On the same evening severe pain, accompanied with intolerable headache of a bursting and throbbing character, was marked and whilst the discharge from the ear became less the external auditory meatus was seen to be inflamed. This inflammation increased and extended to the external ear and the whole auricular region became hot, red, and swollen, whilst the lymphatic glands in the vicinity were enlarged and extremely tender.

I was called in to see the patient on April 19th and found her suffering from severe erysipelas extending almost over the whole right half of the head and forwards on the face to the outer canthus of the right eye. The cervical glands were enlarged and tender, the bowels were constipated, the urine was scanty, the tongue was coated, and she felt exceedingly drowsy. I prescribed the usual remedies and telegraphed to Calcutta for antistreptococcic serum which arrived on the morning of the 21 st. 'The patient was then in a very low state, the inflammation extending still further, the drowsiness was more marked, and the extremities became cold; the temperature, which was still high, went up to $104^{\circ}$, the pulse was 120 , and the respirations were 32 . At 10 A.M. I injected five cubic centimetres of the serum and at 3 P.M. the temperature commenced to fall till 4.15 P.M., when it was $102 \cdot 6^{\circ}$. She then passed urine which was cloudy and loaded with sediment and the tongue became moist. At 6.30 P.M. I again injected five cubic centimetres of the serum, the temperature being $103.4^{\circ}$, the pulse 116 , and the respirations 28 . The condition of the patient still further improved, the urine passed at 7.30 P.M. was clearer and in larger quantity, she sweated, and the lower extremities became warmer; the temperature also fell to $102^{\circ}$. On the 22nd there was noted a marked increase in the area of inflammation extending over the nose and face implicating both eyes and spreading laterally over the right side of the neck; she also complained of a pain in the throat when swallowing, groaned frequently, and continued drowsy. Throughout the day her temperature remained about $102^{\circ}$, the pulse was 128 , and the respirations 28. At 1 A.M. on the $23 \mathrm{rd}$ the pulse became intermittent, the respirations a little hurried, there was a rattling noise in the throat, and subsultus tendinum was marked. On the 23rd the patient passed four or five semi-solid stools and the urine was drawn off by catheter and she appeared somewhat better. At 4 A.M. on the 24th there were convulsive movements of the limbs and body followed by perspiration and the temperature came down to $100^{\circ}$. The inflammation had now spread all over the face and neck, affecting the throat and on this account much difficulty in breathing and swallowing was experienced, whilst the patient remained in a semi-conscious state. As her condition was serious I injected a full dose-viz., ten cubic centimetres-of the serum. In the afternoon she became conscious, complained of pains all over the body, and could swallow nourishment. At 8 P.M. five cubic centimetres of the serum were injected. On the morning of the 25th the inflammation had extended to the shoulder and back of the chest, but it was particularly noted that the inflammation had receded considerably from the previousir attacked parts and the right eyolids were less cedematous. The patient herself felt much better and could taik and swallow fluid food without difficulty. As steady improvement continued under the serum treatment I injected five cubic centimetres more of the serum in the morning, and whilst the inflammation spread half way down the back, yet its margin was not very raised, it was more superficial and it extended less actively than heretofore. On the 26th the patient's condition remained unchanged, except that she complained of some tightness of the chest accompanied by occasional cough and expectoration of some frothy mucus; on auscultation the base of the right lung was found to be somewhat congested. On the 27th two injections of five cubic centimetres each were given and the effect was very marked upon the inflamed area, as evidenced by its not extending, the gradual disappearance of its colour, and the absence of a raised margin. 'The patient's progress, hitherto satisfactory, now took on a new paase, the congestion of the lung above noted becoming a consolidation and the symptoms of the pneumonia completely masked those of the primary complaint. From April 27th to May 2nd the patient's condition was such that little or no hope was given of her recovery. The recurrence of fever, together with the hurried respirations and the frequent dry and troublesome cough, produced great prostration, but under appropriate diet and treatment, with very careful nursing, respiration became easier on the 1st and the lungs began to clear. The patient's temperature now became subnormal and she continued to make uninterrupted progress towards recovery.

CAst 2.-A young Hindoo female, aged 18 years, was delivered of her first child on July 16th, 1904. On the third day after delivery she had slight fever, of which no notice was taken; she was apparently doing well until the 23rd when she again had fever which continued with daily exacerbations each erening until August 1st, when I was called to see the case. Her condition was then as follows. The temperature was $103 \cdot 3^{\circ} \mathrm{F}$, the pulse was 96 , and the respirations were 20 . The tongue was thickly coated and the bowels were regular. There was no complaint of pain and there was no tenderness on pressure over the uterine, region. The lady doctor who was in attendance on her at the time of delivery informed me that though the lochial discharge was now sweet, yet at 
the time there occurred a partial rupture of the perineum, which had not been sewn up. The patient complained of severe headache at intervals and after a careful inquiry into the history of the case I was convinced that the symptoms above noted were due to septic infection and that I was justified in exhibiting antistreptococcic serum. I therefore injected the last bottle containing ten cubic centimetres of the supply used in the previous case-viz., that prepared at the Wellcome Physiological Research Laboratories (Series 136, dated Feb. 9th, 1904)-and wired for a further supply. The following day the patient felt much better and tbe temperature came down to normal. Meantime the lady doctor syringed the uterine cavity with an antiseptic douche On the morning of the 3rd a new supply of the serum arrived (Series A14, dated May 16th, 1904) and as the symptoms of sapræmia persisted an injection of ten cubic centimetres was at once administered. The effect of the injection was soon manifest as the temperature, which was then 103.2 $2^{\circ}$ had next morning fallen to normal and the other concomitants abated in like manner; the patient convalesced quickly and had no further return of the symptoms.

In a paper on Puerperal Sepsis ${ }^{3} \mathrm{Dr}$. P. Horrocks sars: "Of antistreptococcus serum I have had a large experience and in some cases it seems to act wonderfully well but it so often fails that I fear that at present one must admit that it is unsatisfactory." It may be possible, however, that since that paper was written the new issues of serum are more trastworthy and certainly in cases where the cause is undoubted-viz., a simple septicæmia or a sapræmia--good results can be obtained by the use of the serum. T'o achieve the best result the following factors seem necessary :-

1. That where the infection is "single" and a polyvalent serum is obtainable possessing the "immune body" it should be applied as soon as the illness is recognised, the object being to inject before much toxin has formed.

2. That the serum should be as fresh as possible.

3. In his Goulstonian lecture (1903) Dr. A. S. F. Grünbaum says: "Nor will any harm arise from a dose beyond what is necessary for mere neutralisation of the toxin; on the contrary, the excess may dissociate a union of toxin and cell already completed." Therefore, in those cases in which the serum is doing good there is no danger in administering an excess and also from the abore arises a second corollary - viz, that in those cases where there is no apparent benefit there is no evidence to show that it does harm.

4. That since the serum acts mainly by increasing phagocrtosis and since in certain cases very little antidote is formed the administration of the serum should be continued for some time after apparent recovery until its action is quite complete.

For the full and comprehensive notes on Case 1 I am indebted to Assistant Surgeon Uma Prasanna Ghose, who was in constant attendance on the patient.

Dhubri, India.

\section{NOTES OF MIDWIFERY CASES IN MADAGASCAR.}

BY C. F. A. MOSS, M.D. EDIN.

MEDICAL MISSION, TANANARIVO, MADAGASCAR.

DURING a residence of some 15 years in Tananariro there have occurred in my practice several milwifery cases of more or less interest. It is not my purpose to give any exhaustive account of obstetrical conditions in Madagascar, as unfortunately in a general practice there has not been the requisite range of cases or opportunity to collect the large number of facts which are needed for any scientific study. The total number of cases on my list is 135 , of whom 58 were Europeans and 77 were natives. Divided according to the sex of the offspring I find that during my first term (eight, vears) amongst the European births 15 were male and eight were female and amongst the natives 17 were male and seren were female; during the second term, of Furopean births 72 were male and 23 were female, of natives 25 were male and 21 were female; in seven cases the sex was not recorded. Forceps were applied 37 times, 11 of these being in Europeans; one case died from septicæmia developed late in the

${ }^{3}$ Erit. Med. Jour., Feb. 13th, 1904, p. 349. puerperium; seven of the children were stillborn, at least two being dead before assistance was sought. The conditions for which forceps were applied were: inertia, 15 cases (nire Europeans) ; placenta prævia, two cases ; pelvis justo-minor four cases ; rickets, tbree cases ; spondylolisthesis, four cases (the same indiridual); male pelvis (?), one case; forehear presentation, two cases; and right occipito-posterior, for $\mathrm{r}$ cases. Placenta prævia occurred 12 times in my cases; one died from post-partum hæmorrhage and six children were stillborn. Other complications were: transverse presentations, four cases ; twins, five cases ; atresia of os externum one case; post-partum hæmorrhage, four cases ; anc hydramnios, four cases (accompanied severally by placenta prævia, one of twins, and great malformation-meningocele, supernumerary digits, eyelids not separated, no septum nasi, very small mouth, and rudimentary teeth). These ftxw statistics are of very small value.

Pelvic deformities are not of great frequency. Pelvis justominor is perhaps the most common variety.

Rickety pelvis is rare. For an advanced case of this I did symphysiotomy, after which the child was delivered fairly easily with forceps; it was aspbyxiated but recorered. Much attention was paid to the asepsis but the patient rery rapidly developed septicæmia and died. A probable explanation was to be found in the fact of ber having ozæna and so being likely to infect herself with her fingers which were probably placed on the vulva.

Spondylolisthetic pelvis.-A patient with a markerl deformity of this character has returned to me for the fourth time for delivery. She was of good height and build and there was no evidence of the deformity until examination was made. The antero-posterior diameter of the pelvis was then found to be shortened by a large bony protuberance occupying the usual position of the sacrum and with its convexity airected towards the vagina. Its surface was not smooth, there keing oblique ridges running downwards across it from left to right. The diagonal conjugate was three inches. The patient has had five children; the first was delivered in the country by craniotomy after a long delay. For the second she was brought to hospital, the head having been low down in the pelvis for seven hours. Forceps were put on and delivery completed, the child being alive but having a deep depression with sharp edges orcr the left side of the forehead above and below the coronal suture. This gare rise to a good deal of anxiety lest untoward symptoms should arise but nothing extraordinary appeared. The child, who is now nine jears old, is very bright, so much so that he learnt to read in a month and the depression only appears now as a slight flattening. The third child was delivered with but slight delay; the head was driven well down but could not entirely pass the obstruction, therefore forceps were again applied. The depression was exactly as before. The fourth and fifth children were similarly delivered. There is no history of damage to the pelvis at any time or of any period of illhealth as a child, and the onset of the deformity canr ot be traced. It appears stationary, as the depression it causes in the child's head is always precisely the same. No attempt has been made in the case of either of these children to raise the depressed bone, as the children bave not appeared to suffer in the slightest degree therefrom ant the depression has decreased so much that no very marked deformity has been left.

Funnel-shaped pelvis with vesico-raginal fistula.-The patient had had two children and was brought to hospital after being in labour some hours. On examination the rectovaginal wall was missing for a considerable distance. The cervix was felt as a soft protuberance directed posteriorly but the os uteri was nowhere to be found. The foetal hear was plainly detected through the tissues in the vaginal renf and had entered the pelvis. About an inch from the ostimm vaginæ in the middle line of the anterior vaginal wall there was a small round orifice just la'ge enovgh to admit the tip of the index finger; its erlges were sharply defined and stretched. The foctal head actual is presenter in this orifice and the membranes were still unr ptured. The contractions of the uterus clid not serve to dilate this orifice and there was no further descent of the hearl into the pelvis. The bony pelvis was contracted at the outlet; from the rough observations made the conjugate was a little less than three inches and the transverse dirmeter less still. The history given was that this was the second pregnancy, that the first was terminated by mutilation of the child and followed by incontinence of fæces dce to the sloughing away 